\title{
Prolonged closed cardiac massage using LUCAS device in out-of-hospital cardiac arrest with prolonged transport time
}

This article was published in the following Dove Press journal:

Open Access Emergency Medicine

6 May 2009

Number of times this article has been viewed

\author{
Edouard Matevossian' \\ Dietrich Doll ${ }^{4}$ \\ Jakob Säckl' \\ Inga Sinicina ${ }^{5}$ \\ Jürgen Schneider ${ }^{2}$ \\ Gerhard Simon ${ }^{3}$ \\ Norbert Hüser' \\ 'Department of Surgery, \\ ${ }^{2}$ Department of Anesthesiology \\ and Intensive-Care Medicine; \\ ${ }^{3}$ Department of Radiology, Technische \\ Universität of Munich, Germany; \\ ${ }^{4}$ Department of Visceral, Vascular \\ and Thoracic Surgery, Philips \\ University of Marburg, Marburg \\ Germany; ${ }^{5}$ nstitute of Clinical \\ Forensic Medicine, Ludwig-Maximilian \\ University of Munich, Munich, Germany
}

Correspondence: Edouard Matevossian Department of Surgery, Technical University of Munich, Ismaninger Strasse 22, D-81675 Munich, Germany

$\mathrm{Tel}+49894 \mid 407395$

Fax +4989 4I 40 48I5

Email matevossian@chir.med. tu-muenchen.de

\begin{abstract}
Saving more human lives through more effective reanimation measures is the goal of the new international guidelines on cardiopulmonary resuscitation as the decisive aspect for survival after cardiovascular arrest is that basic resuscitation should start immediately. According to the updated guidelines, the greatest efficacy in cardiac massage is only achieved when the right compression point, an adequate compression depth, vertical pressure, the correct frequency, and equally long phases of compression and decompression are achieved. The very highest priority is placed on restoring continuous circulation. Against this background, standardized continuous chest compression with active decompression has contributed to a favorable outcome in this case. The hydraulically operated and variably adjustable automatic Lund University Cardiac Arrest System (LUCAS) device (Jolife, Lund, Sweden) undoubtedly meets these requirements. This case report describes a 44-year-old patient who - approximately $15 \mathrm{~min}$ after the onset of clinical death due to apparent ventricular fibrillation - received cardiopulmonary resuscitation, initially by laypersons and then by the emergency medical team (manual chest compressions followed by situation-adjusted LUCAS compressions). Sinus rhythm was restored after more than 90 min of continuous resuscitation, with seven defibrillations. Interventional diagnostic workup did not reveal a causal morphological correlate for the condition on coronary angiography. After a 16-day period of hospital convalescence, with preventive implantation of an implantable cardioverter defibrillator and several weeks of rehabilitation, the patient was able to return home with no evidence of health impairment.
\end{abstract}

Keywords: resuscitation, cardiac arrest, cardiac massage, LUCAS

\section{Case report}

A 44-year-old patient, who did not have a relevant cardiopulmonary or cerebrovascular risk profile, collapsed postprandially at $0015 \mathrm{~h}$ from a sitting position, with no prodromal symptoms, in the presence of his family. When the emergency medical team arrived $(0030 \mathrm{~h})$, the clinically dead patient (with respiratory and cardiac arrest, bilateral equally dilated fixed nonreactive pupils, and bilateral massively congested jugular veins) was lying on his back on the floor. After immediate commencement of treatment with closed cardiac massage and orotracheal intubation, the rhythm analysis showed ventricular fibrillation, and several defibrillations (a total of $7 \times$ at $200-360 \mathrm{~kJ}$ ) and high-dose fractionated intravenous administration of adrenaline (epinephrine at $1 \mathrm{mg}$ max. single doses, total $30 \mathrm{mg}$ ), atropine $(1 \mathrm{mg})$ and amiodarone $(300 \mathrm{mg})$ were therefore carried out. In view of the hemodynamically unstable situation, with a probable transport time to the nearest hospital of approximately $20 \mathrm{~min}$ for the patient and inevitable physical exhaustion during administration of cardiac massage submit your manuscript | www.dovepress.com

Dovepress which permits unrestricted noncommercial use, provided the original work is properly cited. 
(with the two-helper method), the Lund University Cardiac Arrest System (LUCAS; Jolife, Lund, Sweden) was used for further standardized chest compressions, adjusted in accordance with the situation and the patient (frequency $80 / \mathrm{min}$, located at the central sternum, compression depth $10 \mathrm{~cm}$; Figure 1). During further resuscitation measures subsequently undertaken in hospital, a sinus rhythm with spontaneous circulation and an invasively measured systolic pressure of 135-140 $\mathrm{mmHg}$ was then restored (at approximately 0140 h).

Subsequent coronary angiography in this patient showed limited left-ventricular function with anterolateral cardiac hypokinesia, with no evidence of high-grade stenoses in the area of the coronary vessels (Figures $2 \mathrm{a}, 2 \mathrm{~b}$ ). In addition, first- to second-degree mitral valve insufficiency with intermittent atrial fibrillation was diagnosed. The following day, the patient developed ventricular fibrillation again at $0630 \mathrm{~h}$ (approximately $6.5 \mathrm{~h}$ after the first event), which was managed with three sequential defibrillations and systemic administration of $300 \mathrm{mg}$ amiodarone. After the patient had been hemodynamically stabilized, an implantable cardioverter defibrillator (ICD; Medtronic Maximo VR 7232 VV100) was implanted. On the ninth day of hospitalization, it was possible to extubate the patient without problems, with adequate gas exchange and no evidence of relevant cerebral ischemia. After a 16-day hospitalization period and several weeks of rehabilitation, the patient returned to his family with no evidence of any impairment of health.

A clinical and machine-diagnostic reevaluation of the patient four months after the event showed a state of complete convalescence, with no signs of a cerebrovascular lesion caused by the resuscitation procedures.

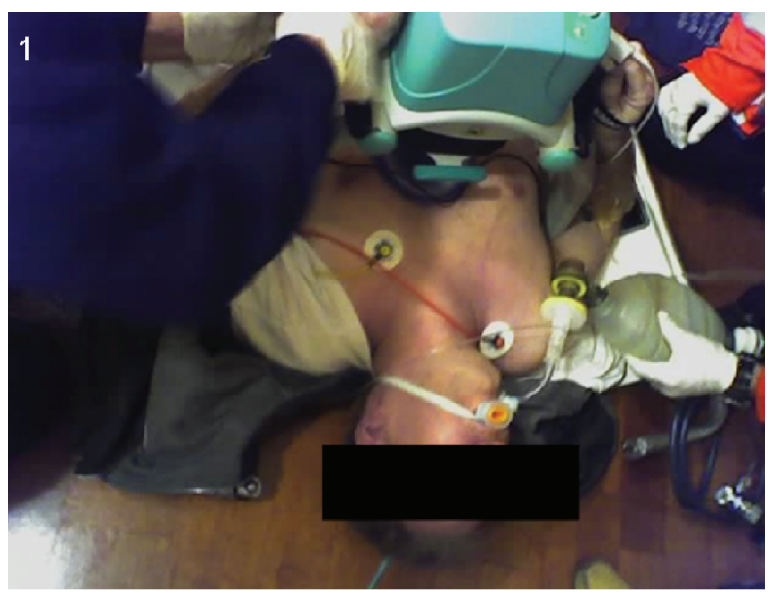

Figure I LUCAS during resuscitation. Jugular venous distension during circulatory shock of the intubated and mechanically ventilated patient.

\section{Discussion}

Despite improved medical training and all the advances in medical technology, only $7 \%-11 \%$ of all resuscitation procedures are primarily successful. ${ }^{1}$ In Germany, more than 100,000 people suffer sudden cardiac death annually, although the occurrence of cardiovascular arrest need not be synonymous with death. ${ }^{1}$ The goal of the new international guidelines on cardiopulmonary resuscitation in adults, children, and infants is to save more lives through more effective resuscitation measures. ${ }^{2,3}$ Survival after cardiovascular arrest depends to a significant extent on basic resuscitation being started immediately. ${ }^{4}$ In a development phase lasting more than two years, the American Heart Association, the European Resuscitation Council (ERC), and other organizations under the egis of the multidisciplinary International Liaison Committee on Resuscitation (ILCOR) have comprehensively reviewed and evaluated all of the new findings on resuscitation procedures, using an elaborate evidence-based process.

According to the new guidelines, the greatest efficacy in cardiac massage is only achieved when the correct compression point is precisely observed. ${ }^{5-7}$ Additional prerequisites for successful resuscitation are adequate compression depth, vertical pressure, the correct frequency, and equally long compression and decompression phases. It is only in these ways that adequate perfusion pressure can be achieved without aids, based on the principle that restoring continuous circulation must take priority and that adequate oxygen reserves must still be present in the perialveolar blood, at least initially. ${ }^{7}$ Numerous experimental and clinical studies have previously shown that even a brief interruption of chest compressions has a markedly negative effect on survival., ${ }^{8,9}$ Against this background, it is obvious that standardized, patient-adjusted continuous chest compressions with active decompression, particularly when there is likely to be an extended pre-hospital resuscitation interval, have a high priority. When there is a prolonged resuscitation period outside hospital (due to the transport time to the hospital, limited numbers of rescuers competent in resuscitation, as well as physical exhaustion, which results in suboptimal cardiac massage), these prerequisites can be fulfilled by the hydraulically operated, variably adjustable automatic LUCAS device. $^{10}$

The present case report describes a 44-year-old patient who received cardiopulmonary resuscitation approximately 15 min after the onset of clinical death due to apparent ventricular fibrillation of unclear origin. As the situation was relatively unfavorable initially in prognostic terms, the 

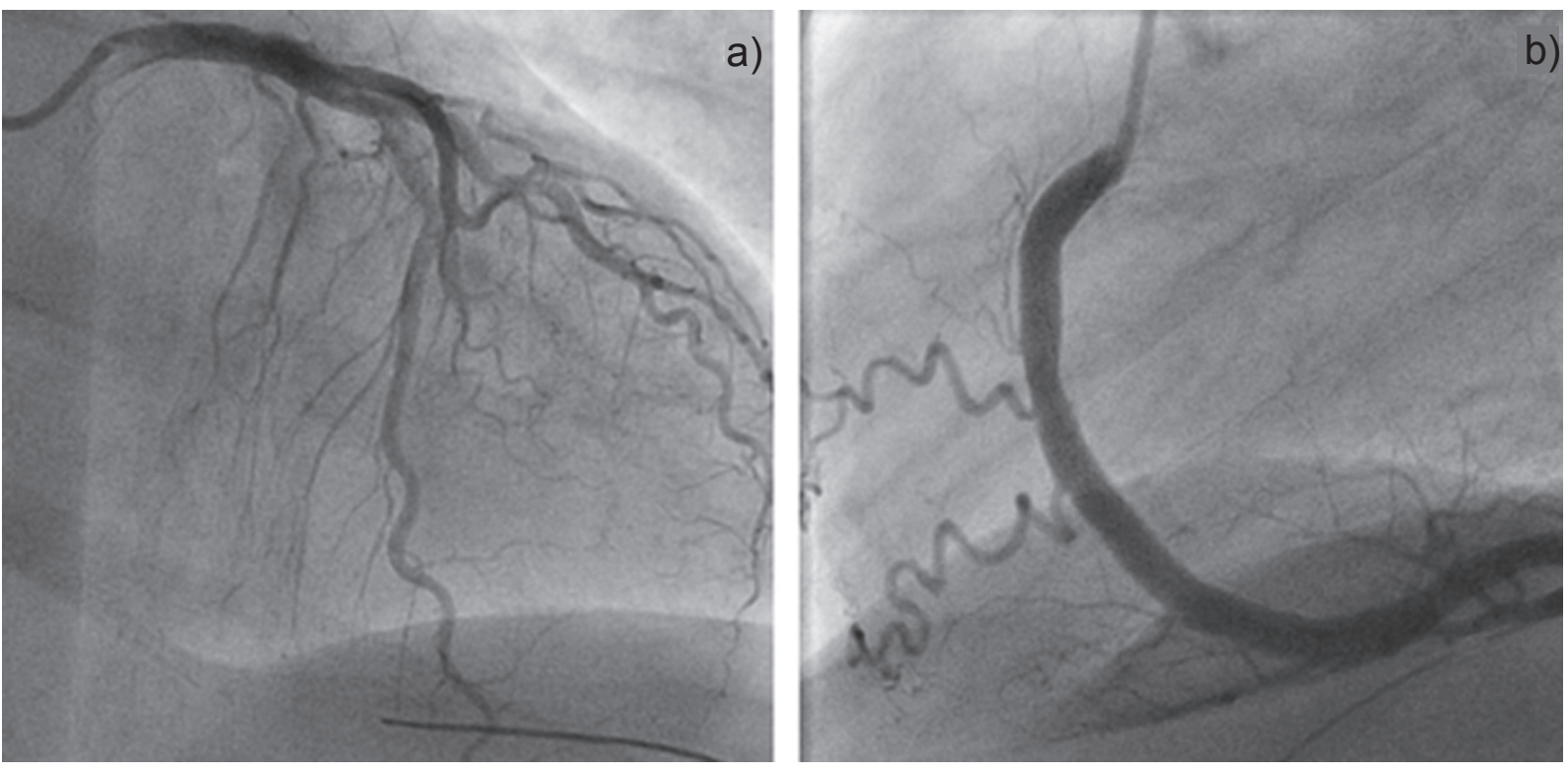

Figure 2 Coronary angiography: a) left coronary artery (LCD), left diagonal artery (LAD), and b) right coronary artery (RCA) without signs of relevant stenosis.

LUCAS device was applied, adjusted to the situation, after 25 min of manual chest compression (using the two-helper method) even before the start of transport. After more than one hour of continuous resuscitation, with seven defibrillations and medical treatment, a sinus rhythm with spontaneous circulation was restored. Subsequent interventional diagnosis with coronary angiography did not identify a plausible morphological correlate capable of causally explaining the preceding cardiovascular arrest. After a 16-day hospital convalescence period, with preventive implantation of an ICD pacemaker and several weeks of rehabilitation, the patient was able to return to his family without lasting injury.

In this case, the use of the hydraulically operated LUCAS device after the start of manual chest compression appears with hindsight to have been important. In view of the hemodynamically unstable situation, and taking into account the expected transport time, the time required to prepare the patient for transport and the inevitability of physical exhaustion during the performance of cardiac massage (with the two-helper method), the LUCAS device was applied, adjusted to the situation and the patient, in order to administer further standardized chest compression.

The first use of a mobile resuscitation device in infants was reported in 1949. ${ }^{11}$ The use of a mobile mechanical system to carry out chest compression in patients with cardiovascular arrest has been described many times previously in the relevant literature. ${ }^{10,12-15}$ Larsen and colleagues, for example, reported retrospectively on the results of coronary angiographic examinations in 13 patients who had suffered cardiovascular arrest. Using the LUCAS device, inadequate perfusion of the descending interventricular branch was only observed in two patients; in addition, no resuscitationrelated intrathoracic or abdominal injuries were noted. ${ }^{12}$ Steen and colleagues presented a prospective study including 100 patients $(58 \%$ with asystole, $42 \%$ with ventricular fibrillation), in whom the resuscitation procedure with LUCAS was started after an interval of more than $15 \mathrm{~min}$ between the cardiac event and the start of chest compressions. ${ }^{10}$ According to the authors' findings, early establishment of cerebral circulation after cardiovascular arrest must be regarded as the most important goal. Relevant adverse collateral lesions such as fractures of the sternum or ribs, with or without pneumothorax - which are theoretically possible with the use of this type of mechanical system - have not yet been reported (in the present case, there were only local skin lesions in the sternal compression area).

Whether or not to apply the increasingly used LUCAS device in the context of resuscitation has to be decided on an individual basis, after contraindications have been excluded. Measures involving early defibrillation, primary manual chest compression, drug therapy and intubation are not affected by the device. ${ }^{16}$ In summary, on the basis of the present case report, the use of a mechanical chest compression system has been found to contribute to a favorable outcome in the context of prolonged out-of-hospital cardiopulmonary resuscitation.

\section{Disclosure}

The authors report no conflicts of interest in this work. 


\section{References}

1. Sefrin P. Reanimation-eine Herausforderung für jeden Arzt. Kongressbericht auf dem 28. Interdisziplinären Forum der Bundesärztekammer, Würzburg. Dtsch Ärztebl. 2004;101:966-997.

2. ERC European Resuscitation Council. 2009. Accessed on Feb 10, 2009. Available from http://www.erc.edu/.

3. ERC European Resuscitation Council. Guidelines for resuscitation 2005. Resuscitation. 2005;67(Suppl 1):1-189.

4. Morley PT, Zaritsky A. The evidence evaluation process for the 2005 International Consensus Conference on cardiopulmonary resuscitation and emergency cardiovascular care science with treatment recommendations. Resuscitation. 2005;67:167-170.

5. Sefrin P. Grundlagen der Basisreanimation bei Erwachsenen. Dtsch Ärztebl. 2005;102:1017-1022.

6. International Liaison Committee on Resuscitation. 2005 International Consensus on Cardiopulmonary Resuscitation and Emergency Cardiovascular Care Science with Treatment Recommendations. Part 1: introduction. Resuscitation. 2005;67(2-3):181-341.

7. International Liaison Committee on Resuscitation. 2005 International Consensus on Cardiopulmonary Resuscitation and Emergency Cardiovascular Care Science with Treatment Recommendations. Part 5: Acute coronary syndromes. Resuscitation. 2005;67(2-3): 249-269.

8. Berg RA, Hilwig RW, Ewy GA, Kern KB. Precountershock cardiopulmonary resuscitation improves initial response to defibrillation from prolonged ventricular fibrillation: a randomized, controlled swine study. Crit Care Med. 2004;32:1352-1357.
9. Eftestol T, Sunde K, Steen PA. Effects of interrupting precordial compressions on the calculated probability of defibrillation success during out-of-hospital cardiac arrest. Circulation. 2002;105(19): 2270-2273.

10. Steen S, Sjöberg T, Olsson P, Young M. Treatment of out-of-hospital cardiac arrest with LUCAS, a new device for automatic mechanical compression and active decompression resuscitation. Resuscitation. 2005;67(1):25-30.

11. Joyce JB. Mobile resuscitation trolley. J Obstet Gynaecol Br Emp. 1949;56(6):1044.

12. Larsen AI, Hjornevik AS, Ellingsen CL, Nilsen DW. Cardiac arrest with continuous mechanical chest compression during percutaneous coronary intervention. A report on the use of the LUCAS device. Resuscitation. 2007;75(3):454-459.

13. Vatsgar TT, Ingebringtsen $\mathrm{O}$, Fjose LO, Wikstrom B, Nilsen JE, Wik L. Cardiac arrest and resuscitation with an automatic mechanical chest compression device (LUCAS) due to anaphylaxis of a woman receiving caesarean section because of pre-eclampsia. Resuscitation. 2006;68:155-159.

14. Holmström P, Boyd J, Sorsa M, Kuisma M. A case of hypothermic cardiac arrest treated with an external chest compression device (LUCAS) during transport to re-warming. Resuscitation. 2005;67:139-141.

15. Wik L, Kiil S. Use of an automatic mechanical chest compression device (LUCAS) as bridge to establishing cardiopulmonary bypass for a patient with hypothermic cardiac arrest. Resuscitation. 2005;66(3):391-394.

16. Petrie DA, De Maio V, Stiell IG, Dreyer J, Martin M, O’Brien JA. Factors affecting survival after asystolic cardiac arrest in a basic life support-defibrillation system. CJEM. 2001;3(3):186-192.
Open Access Emergency Medicine

\section{Publish your work in this journal}

Open Access Emergency Medicine is an international, peer-reviewed, open access journal publishing original research, reports, editorials, reviews and commentaries on all aspects of emergency medicine. The manuscript management system is completely online and includes a very quick and fair peer-review system, which is all easy to use.

\section{Dovepress}

Visit http://www.dovepress.com/testimonials.php to read real quotes from published authors. 